\title{
Editorial The rights of children and the duties of adults
}

We spent much time pondering which title to give to this Editorial.

More suggestive and emotionally strong titles came to mind.

The "billboards" could have been more provocative.

Such as: "Better adults and finally respected children", "When will we have the real century of the child?", "The crushed society" and more.

The issue contains a story on modern and old child abuses, their shapes may vary but the substance does not, it has never been interrupted, with never forgotten memories and new subtler expressions of abuse.

Then, we opted for a drier title, about rights and duties.

In times like ours under many aspects - whether for duties of a personal, relational, professional, social or political nature -, they seem to have been forgotten (we could say that we chose to forget them), transposing rights with desires. Sometimes, the latter are not even legitimate. They carry the flavour of egoism, (a large array of) fragilities, follies and perversion.

Favouring lies over truth.

Often, unmentionable personal profits prevail over the common good.

Persons lie to themselves and to others unwittingly.

They even seem surprised if their wrongdoings are stigmatised by honest people. We refer to intellectual honesty that we believe to be the main form of honesty: things must be called by their correct name. Not the name that we find more suitable to the situation.

Nevertheless, present society stays in the background and acts as context for the array of themes in this issue. The society that was called "liquid" by the late Bauman decades ago, and that two of our group termed "aerial" already in 2009.

Moreover, the title we chose and the ones abandoned speak about our deeper beliefs.

In a purely pedagogical perspective.

Therefore, the entire present issue of "Education Sciences \& Society" is authentically pedagogical. It interfaces with a missing or totally insufficient education. Which should be quickly implemented. To avoid the trap of making mere declarations, just to be at peace with the conscience, while in reality, they do not change a comma in the story: "the crisis of education", "parents should be trained", "the family to be rescued or restored" and more. 
Furthermore: this issue deals with a finally necessary pedagogy. In a context of less attentive analyses, less prone to affect contemporaneity, which sometimes interprets contemporaneity in a distort or biased manner.

The need of a pedagogy that chooses to descend even into darkest realities to provide them with light again. It should not stroll above the stars but lift (all) the manholes in our villages and cities, open wide the doors of many houses, without running away from the camps where refugees and immigrants are "received". On the contrary, it should meet them at an early stage, on the places of departure and in crossing the Mediterranean. Especially the minors, boys and girls, teenagers of both sexes abused and raped. Especially those "unaccompanied". One in four of them disappears before the trip or just after landing. Where? How? When? Why? Where are they sent? To which sordid unhappy markets? In the hands of which merchants?

Let us abandon emotions immediately, however, we do not escape from them: on the contrary, we want to rescue the lucidity of analysis and of the pedagogical-educational proposals. Nearly at 360 degrees, despite the short space at our disposal in one issue of a journal.

While we continue, unmovable and relentless, to support a pedagogy that inhabits, immediately and vigorously, the present tense in all its manifestations.

Useful for every one of us, all included. It should accompany the journey and growth, attentive and considerate, affective, in all life choices.

So that teenagers and adults, women and men, may decide and decide again their lives with more awareness.

Then, maybe, Italian pedagogy could sell a few more books. It will not find its monographs again bundled and disorderly stacked on the shelves, these books are often the less valuable ones or typically local, alongside divulging texts on paediatrics, food science or cheap psychology.

While, prestigious tomes on psychology, sociology, history and philosophy have been occupying for a long time orderly and fruitful shelves.

We are not pessimistic, but this is the result of many visits to big and small bookstores from Northern to Southern Italy.

Books on pedagogy translated or received abroad (obviously, we refer to the Italian ones) are very rare.

There is a small, in progress, exception; it favours the texts on didactics that deal with the profession of the teacher or special pedagogy about disabilities and autism.

Let us return to the pedagogical control room that governs these issues epistemologically.

The contents include abuse in education and child abuse.

Inside the pedagogical proprium, which is the educational relationship, the three-dimensional relationship that needs at least one educator (adults), a 
learner (the children, specifically, those of today) and the environment (in this case: society in its various expressions and organisations).

This explains the titles and the "rejected" ones, which return joined as a single indivisible unit.

Starting with society: crushed, lost, liquid or aerial.

Our society is complicated rather than complex. Inherently complicated, self-made complicated. Because of the many interests at stake. Nevertheless, in the hands of few. For all the lies that it tells. And the values that were obliterated. For the extreme immanent form that governs it and the conflictual temporariness that today connotes too many people, couples, families and institutions. Like a prison whose good intentions were rejected, while the key was almost thrown away. For the primacy of pleasure that characterises $i t$. And the patience of the great projects that it abandoned. To run after immediate rewards, the here and now, as well as obtaining all at the same time. It has a formidable fear of old age and death. It finds shelter, stunned and stunning, in the fleeting moment. Swallowing any available drug, without making decisions: the use of many and varied drugs is something capable of blocking the suffering and maturation of the dimension of a project. The latter, instead, is solid and demands solidity to take progressive decisions, always to be monitored. To embrace, instead, the aerial molecule. Many, or the majority, reduced themselves to bubbles of a cheap sparkling wine produced for the suburbs of life.

This is the social context where today's adults grew up: thirty-year-olds and upward. It moulded and shaped them, better, it deformed them.

Namely, those who have the responsibility to educate children, teenagers and adolescents, as well as continue to educate, in a different manner, youngsters and young adults, communicating and trusting faith in the future to come, with courage and virtuous choices. Rejecting all forms of violence for themselves and the others (and lying, which is another violence), without dogmatising the present and teaching how to climb the mountain with a slow but firm pace. "Lento pede": says the sacristan to the pontiff as he enters the Basilica. With no fears for our falls. We rise again sooner or later. Trusting the age of youth, and the more or less wrinkled hand of the accompanying adult. And, later, back in our forces, when we will be finally fathers and mothers of ourselves.

However, the adults of today are the first ones who do not attest the virtues and the fatigue of a project by standing aside to let the young advance.

Should we not wonder if too many fifteen-year-olds (with numbers destined to increase in the next evolutive processes) are violent, drug addicts, affected by sexism viewed as a safe haven, making the present immanent without believing in the future? They exchange intimacy with intimism. They confound 
love with making love. Choosing the first available one, in a disco or in a pub. They fear direct contact (which is one of the indicators that explain, for example, physical and sexual violence against the others: women, children, teenagers, with reference to bullying and cyberbullying): from the virtual social networks, which they frequent excessively, to prostitution, the most heterogeneous one, something they do not disdain, although they have many free of charge opportunities.

The adult, in permanent aesthetic restyling (of body and life), is flanked by the often-illiterate young male body builder and the often-anorexic girl.

Lost adults and confused youngsters.

The former are violent and the latter are the targets of violence.

As if violence could steal the elixir of life from the young.

Violence itself is a gigantic form of rage; it stems from the many deep fears and fragilities of the modern adults and reverberates on the adults of tomorrow. Like a cascade, unless we do not stop the vicious circle, it falls, on the ones yet to be born.

From society to people and from people to an evidently violent society.

A society yet to become where, rather than being each other associates, we are still homo homini lupus, while quite a few animals - as Lorenz and ethology taught us - are more civilised than the humans.

A society and too many individuals, who equivocate, badly and dramatically, love with possession. Ergo, the femicide, and it is a growing phenomenon in our country. Here, men, aged between 25 and 50 or thereabout, play the leading role.

Which kind of education is, therefore, possible in Italy today?

Which education is practised?

Where is the pedagogy?

Locked inside University rooms?

Academy, instead, should come out to read and understand history in the making, as it cannot keep away from itself, despite its painful and dramatic implications. Even sordid and perverse as they are. It should dirty its hands; make them smudgy, should it be needed. But it should renew force and hope in this troubled contemporaneity.

Considering the picture rendered, is there something to wonder about the educational abuse and child abuse, which are the themes of this issue?

In particular, violence on children is what an adult or a young adult feel that they can practice with less fear, in front of greater fears that they believe they cannot handle. Assuming, at this level, more courage and foolishness and the irreverence of folly: they are only "minors", they have no "power", and they will be silent and will be made silent. We even delude ourselves with too 
many institutions that should have, on the contrary, truth at the top of their thoughts and "good practices".

Therefore, deformed adults, married or cohabiting not trained to the stability of life as a couple, parents unprepared (or worse) to parenthood, abused and raped children, a generation growing in the bad footsteps of these parents and mothers: institutions write subscribable documents or statements that will remain unheeded.

Here we find the articles of this issue.

Starting from the contribution on historical reconstruction by Francesca Borruso.

For two reasons.

The first reason is of cultural and scientific nature.

Pedagogy cannot build present and future of education without the cognition of its roots, knowing where it comes from and whatever happened so far, whatever has been thought, etc.

The second reason is strictly linked with the contents.

Whereby, educational abuse and child abuse always existed, and have not yet been defeated.

So much that the "century of the child" - as rightly put by Maria Grazia Riva - proved to be a total failure, if we consider the goals that it prefixed.

Likewise - as argued by Vanna Iori - the Lanzarote Convention of 2007 (which followed the one on rights of the child of 1989) has indeed failed in many of the goals that it promised against exploitation and child sexual abuses.

So Elisabetta Biffi sheds light on the vastness and pervasiveness of the present phenomena of violence, tracing a profile of great complexity and variability. Protection of minors proves to be, in such scenario, - according to the author - a "complex affair" to be addressed and resolved that needs an integrated work by the different sides, about whom the author exposes some possible strategies of prevention and care, at international level too.

Then comes the article by Silvia Demozzi, according to which the violence against childhood is multiple: major and minor, macroscopic and "subtle", like adultisation (making children adults, and adults teenagers!), going against to the "right to childhood" and the respect of its authenticity.

And, above all, there is the great theme of the family and its educational responsibility and also the civil and political ones, always: before, after and during, in relation to the growth and education of the child of today and the person of tomorrow.

The contribution by Daniele Novara shows how violence against children happens every day, and everywhere, starting from the most common violence 
linked with educational methods in the family, which are punitive, physical and psychological.

The article by Tatjana Vujović follows, she focuses her attention on how the parental rejection lived during childhood influences delinquent behaviour in adolescence or adulthood: "rage constantly generates rage", mixed with fears; by Ruth Pinedo Gonzàlez, who highlights the correlation between the experience of stressful events during childhood and adolescence and adult behavioural and social maladjustments. Finally, in such hermeneutic perspective, Ioanna Palaiologou's contribution relates to digital violence on children surrounded by a context of distracted parents or delegating on this subject.

Finally, as we started, we refer to underage immigrants, especially those unaccompanied.

This is the proposal of the paper by Silvia Edling and Guadalupe Francia, they analyse the measures adopted by Sweden to try to prevent the risk of violence and exclusion suffered by the children immigrated in that nation, overcoming the confusion on who is responsible among the many actors in the process of protection.

And, there is the contribution by Serena Sani, who, although present in "Alia", addresses the themes of integration at school and to contrast dispersion in an intercultural and European perspective, highlighting educational strategies and measures for the purpose. It fully re-connects with the overall meaning of this issue since it shows that the average percentage of school leavers in the European Union is double among immigrant students compared with the native ones. In other words, another form of violence perpetrated against the former. As always, ever since its inception the journal ends with the "Pedagogical Lexicon" edited by Stefania Ulivieri Stiozzi and the "Reasoned Bibliography" written by Alessandra Pantaleone.

And now it is time to publish this issue and deliver it to the readers.

We are aware that - going back to Bauman - we only created a drop in the endless ocean made of abuse and violence still perpetrated against our heirs of tomorrow.

However, we all have to do our part, assuming the responsibilities that we have or can exercise. Something will change sooner or later, with political, scientific, institutional lucidity and courage.

This is our utopia.

Furthermore, as for other themes, we configure argumentative and experential planes, which in our hope, form a near certainty.

Michele Corsi, Massimiliano Stramaglia, Elisabetta Biffi, Ioanna Palaiologou 